\title{
Biochemical characteristics of roots and quality of own-rooted planting material of grape varieties tolerant to phylloxera when using biologically active substances and hormones
}

\author{
Ramidin Kazakhmedov ${ }^{* 1}$, and Marina Magomedova
}

Dagestan selection experimental station for viticulture and vegetable growing - a branch of the Federal State Budgetary Scientific Institution "North Caucasian Federal Scientific Center for Horticulture, Viticulture, Winemaking", 9 str. Vavilova, Derbent, 368601, Russia

\begin{abstract}
The aim of the research is to conduct a comparative assessment of the biochemical status of roots and the influence of physiologically active compounds on the formation of the root system of phylloxera-tolerant grape varieties. It was established, that the hormonal status and the content of BAS in the root system of phylloxera-tolerant varieties of interspecific origin are different. It is assumed that the different survival rate of cuttings of $V$. vinifera $\mathrm{L}$. varieties and varieties of interspecific origin are due to different hormonal status, in particular, the level of endogenous auxins and the degree of gene expression, including exogenous use of auxin drugs. On varieties of interspecific origin, with the non-root use of a solution of FAS based on cytokinin, auxin and trophic factor, in a ratio of 10:1:25, the formation of a powerful root system, an increase in the number of heel roots and the number of roots with a large diameter, an increase in the trophic potential of the elements of the root system compared with the pre-planting use of auxin preparation (NUC) is observed. this will contribute to the better development and early fruiting of root-related plants in the following years.
\end{abstract}

\section{Introduction}

It is known that the transition to a grafted grape culture did not allow solving the problem of phylloxera in full and at present it remains relevant. The disadvantages of the grafted culture indicate the relevance of preserving and expanding the grape's own rooted culture. The fundamental solution to the problem should be the creation and introduction of resistant genotypes to the pest on the basis of modern achievements of genetics and selection, suitable for cultivation in own-rooted culture [1-4].

The use of growth regulators is one of the most common ways to increase the quantitative yield of planting material, and the auxin preparation NAA is the most active physiologically [5]. However, the generally accepted pre-planting use of auxins does not always show high efficiency in new interspecific varieties and hybrids tolerant to

\footnotetext{
${ }^{1}$ Corresponding author: kre 05@mail.ru
} 
phylloxera due to their genetic characteristics. It should be noted that cuttings of the phylloxera-immune Vitis rotundifolia species practically do not take root. We consider it urgent to study the influence of physiologically active compounds on the quality of planting material when processing the leaf surface of plants at the initial stages of the formation of the root system.

The aim of the research is to carry out a comparative assessment of the biochemical status of roots and the effect of physiologically active compounds on the formation of the root system of grape varieties tolerant to phylloxera.

\section{Materials and methods}

The research was carried out on the experimental base of the Dagestan selection experimental station for viticulture and vegetable growing - a branch of the Federal State Budgetary Scientific Institution "North Caucasian Federal Scientific Center of Horticulture, Viticulture, Winemaking", in 2018-2020. The object of research is shortened cuttings and seedlings of phylloxera-tolerant 8 grape varieties and Agadai varieties (control). Physiologically active compounds - cytokinin (FAS - 1), auxin (FAS - 2), trophic (FAS - 3) action, root - NAA, $1 \mathrm{~g} / \mathrm{l}$. Planting scheme of varieties $20 \times 10 \mathrm{~cm}$. Repetition 3 -fold (10 cuttings - repetition). The term of application of FAS is to achieve a length of $15-20 \mathrm{~cm}$ by the shoots. Method of application of FAS is to treat the leaf surface of seedlings with a solution of FAS by spraying.

\section{Results and discussion}

The formation of the root system in grape cuttings and morphological elements of the future plant is undoubtedly determined by a number of external and internal factors, including the ratio of hormones and various biologically active substances of organic nature, formed in the leaves of a young plant at the very beginning of the formation of elements of the root system [6-11].

A high ratio of IAA/ABA was found in varieties of complex interspecific hybridization of Moldavian selection and a low ratio in varieties bred by the Magarach Institute (Fig. 1). The analysis of parental pairs of varieties showed that varieties with a high auxin content in the roots of Moldova (Guzal cara x Villar blanc), December (Korna nagra x Villar blanc) and Bianca (Villard blanc $x$ Chasselas bouvier) have Villard Blanc in the genealogy (Seibel $6468 \times$ Seibel 6905), with the genetic formula: 56.19\% Vitis Vinifera $+3.13 \%$ Vitis Labrusca $+29.16 \%$ Vitis Rupestris $+6.25 \%$ Vitis Berlandieri $+5.28 \%$ Vitis Lincecumii.

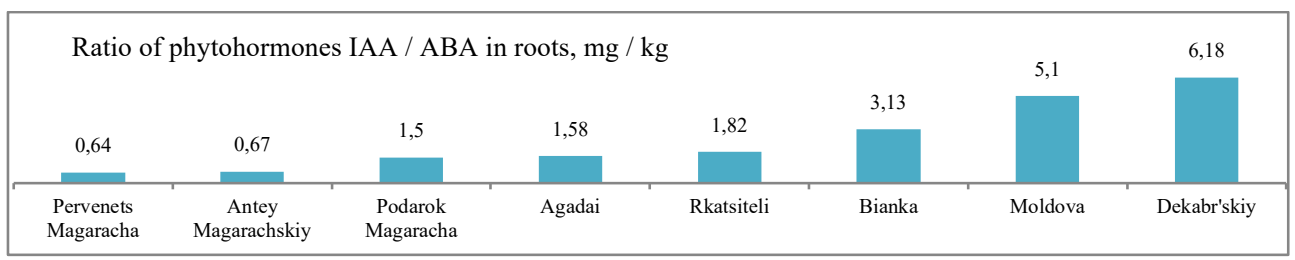

Fig. 1. Content of phytohormones $(\mathrm{mg} / \mathrm{kg})$ in the roots of grape varieties of different resistance to phylloxera

One of the possible criteria for the tolerance of grape varieties to phylloxera is the low content of carbohydrates in the roots. In the group of varieties with prevalence of auxins in the roots over the inhibitor during the growing season, varieties Bianca and Moldova had a minimum carbohydrate content in comparison with other tolerant varieties and Agadai (control, V. vinifera L.). The low content of carbohydrates and the amount of amino acids 
in the Bianca cultivar is accompanied by a high level of phenolcarboxylic acids and aromatic amino acids tyrosine and phenylalanine, which confirms our hypothesis about the role of these amino acids in the formation of resistance to phylloxera. The fact of the conjugation and involvement of carbohydrate and phenolic metabolism in the mechanism of adaptation of a grape plant to a pest remains indisputable (Fig. 2). The tolerant varieties Antey Magarachsky, Dekabrsky, Moldova and Rkatsiteli were distinguished by a higher absolute content of amino acids. At the same time, Antey Magarachsky, Dekabrsky and Bianka distinguished themselves with a high content of tyrosine (Fig. 3).

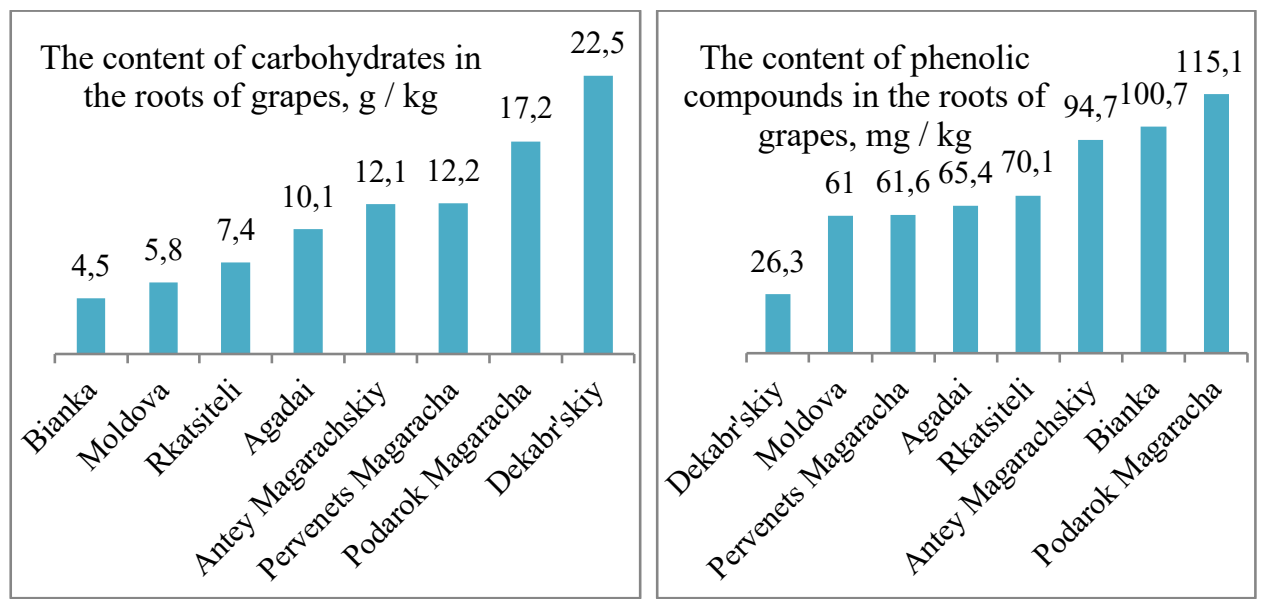

Fig. 2. The content of carbohydrates $(\mathrm{g} / \mathrm{kg})$ and phenolic compounds $(\mathrm{mg} / \mathrm{kg})$ in the roots of grape varieties of different resistance to phylloxera, 2019

We believe that low levels of carbohydrates in the roots in combination with a high ratio of IAA/ABA, the content of aromatic amino acids tyrosine and phenylalanine suggest the physiological resistance of grape plants to root phylloxera.

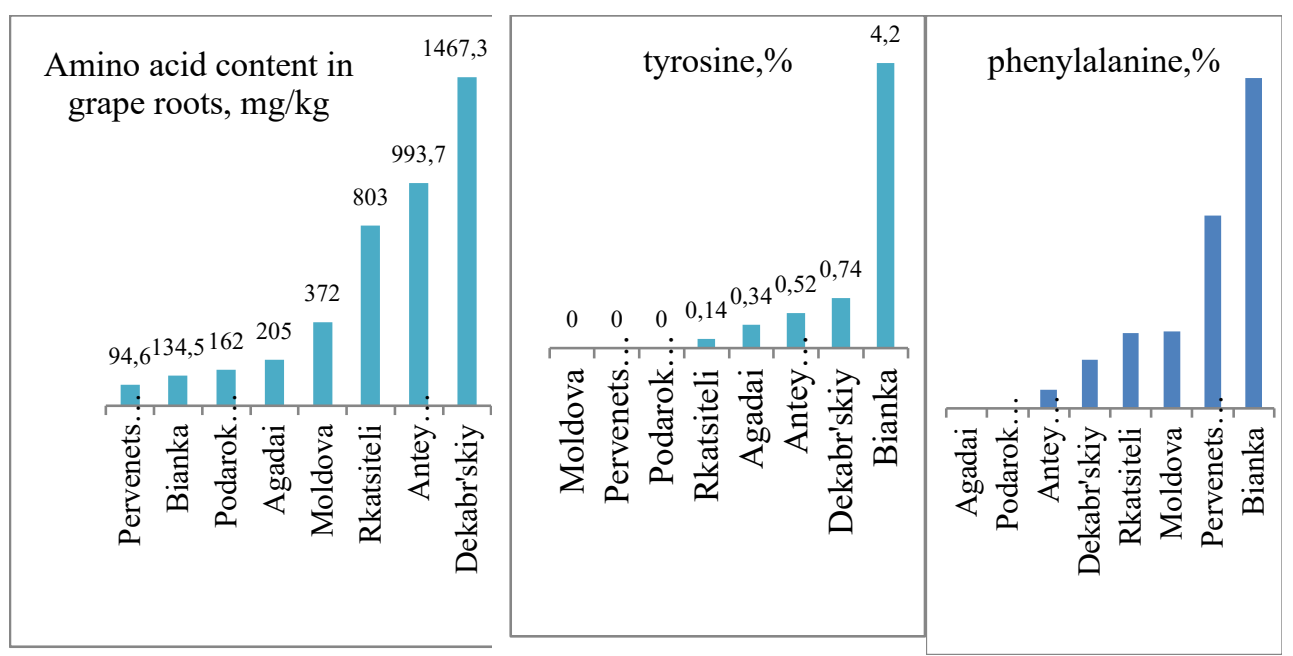

Fig. 3. The content of amino acids $(\mathrm{mg} / \mathrm{kg})$ in the roots of grape varieties of different resistance to phylloxera, 2019

For the first time, the morphophysiological effect of the restoration of the root system with the complete removal of roots by exposure to the leaf surface of plants was revealed on grapes [1]. FAS hormonal and trophic action not only allow the plant to restore the root 
system, but also significantly increase the content of carbohydrates and amino acids in the roots. The content of carbohydrates increased 4-8 times, amino acids - 1.5-4.0 times, in comparison with their content in the roots of the control variant without removing the roots (Fig. 4).
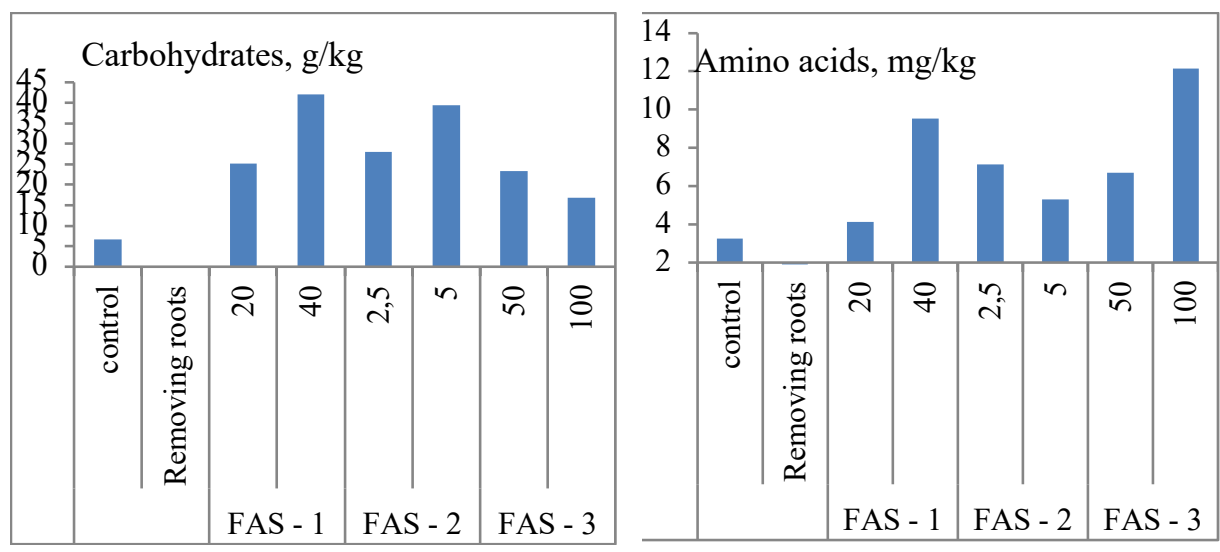

Fig. 4 The content of carbohydrates and amino acids in the roots of Agadai grape plants, when processing FAS

It is known that varieties of interspecific hybridization tolerant to root phylloxera have lower rates of cuttings survival rate than those of Vitis vinifera L. Moreover, cuttings of most varieties of interspecific origin react poorly to the use of auxin preparations. In our study, the survival rate of cuttings of the Bianka variety did not change against the background of soaking in the root, while the survival rate of cuttings even decreased in the varieties Avgustin and Pervenets Magarach (Fig. 5).

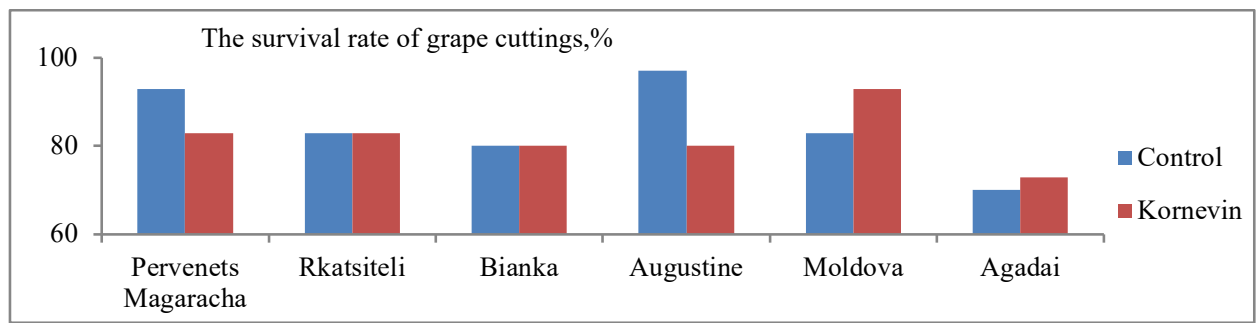

Fig. 5. The survival rate of grape cuttings

Studies have shown that the length of the roots is $3-5 \mathrm{~mm}$ in diameter. in the studied varieties, after foliar treatment of plants, it exceeded the variant with a root by 2-8 times, depending on the variety. When processing FAS, the proportion of roots with a larger diameter increases, and the diameter of the matured part of the shoot in the FAS variant is more than in the control and root variants by $10-40 \%$. The length of the matured part of the shoot in the FAS-1 variant is 1.5 - 2 times greater than the variant with the use of root (Fig. 6).

Foliar application of FAS has a positive effect on the main morphological and physiological parameters of self-rooted seedlings, which determine the quality of the planting material (Fig. 7). Thus, the foliar application of FAS on the leaf surface of young plants of varieties tolerant to phylloxera at the beginning of the establishment of the elements of the root system is more effective than the use of the reference auxin preparation NAA - root. 

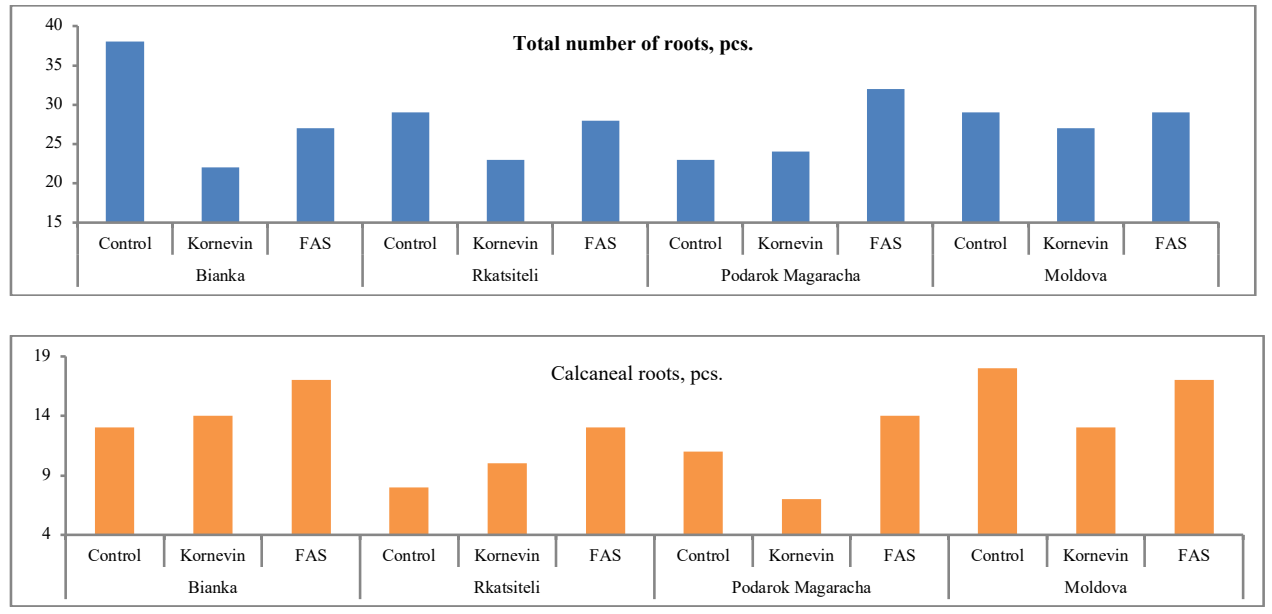

Fig. 6 Influence of FAS on root formation of grape plants with different resistance to phylloxera
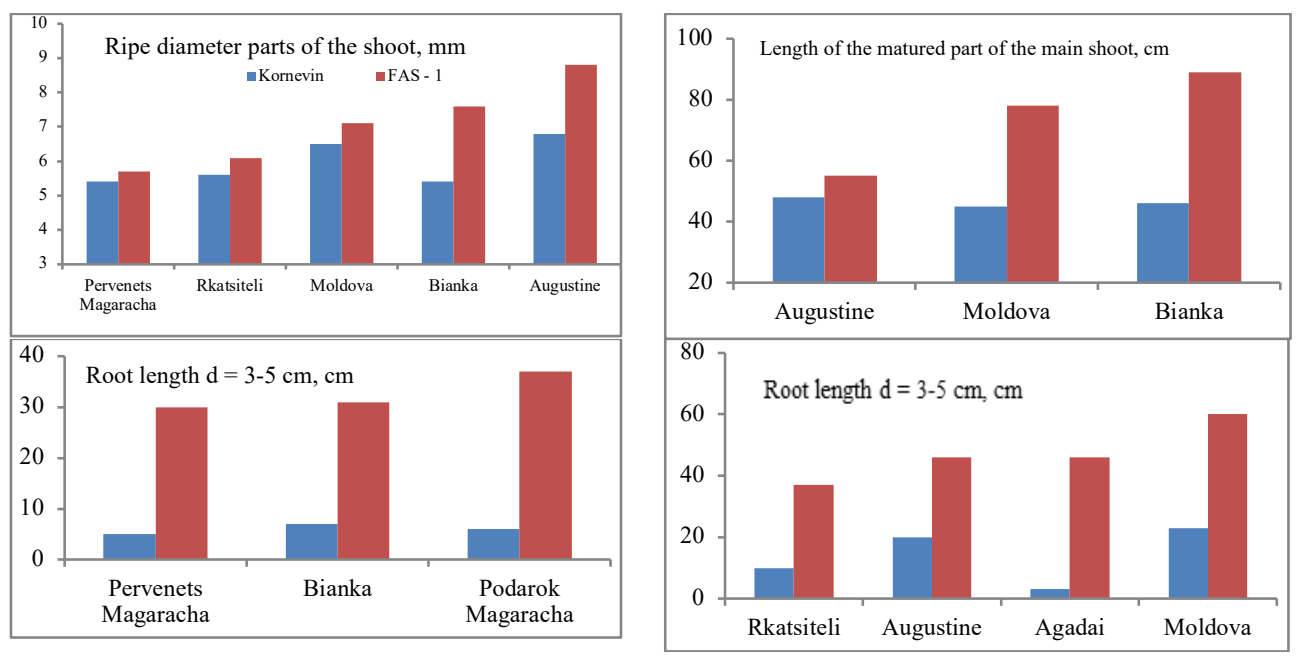

Fig. 7. Influence of FAS on the development of seedlings from shortened cuttings, DSOSViO

\section{Conclusion}

Based on the results of our research and analysis of the literature [1, 7, 8, 11-15], we assume that the different survival rate and response to auxin treatment of cuttings of $\mathrm{V}$. vinifera L. cultivars and cultivars of interspecific origin is due to different hormonal status, in particular, the level of auxins and the degree of gene expression, incl. and with exogenous use of auxin preparations.

Foliar application of an FAS solution based on synthetic auxin and cytokinin compensates for the lack of hormones in a young plant at the beginning of the formation of the root system, contributes to the establishment of an optimal hormonal balance and interaction between the shoot apex (IAA) and roots (CC), which leads to better laying, formation and the development of the elements of the root system and the entire young plant (seedling) of grapes in varieties of interspecific origin in comparison with the use of the auxin preparation root (NAA). 


\section{References}

1. R.E. Kazakhmedov, Agrochemistry 6, 18-26 (2019)

2. D. Benheim, S. Rochfort, E. Robertson, I. Potter, K. Powell, Ann. App. Biol., 161(2):91-115 (2012) https://doi.org/10.1111/j.1744-7348.2012.00561.x

3. K.S. Powell, P.D. Cooper, A. Forneck, Adv. Ins. Phys., 45, 159-218 (2013) https://doi.org/10.1016/B978-0-12-417165-7.00004-0

4. N.C. Lawo, G. Weingart, R. Schuhmacher., A. Forneck, Plant Phys. Biochem., 49, 1059-1063 (2011) https://doi.org/10.1016/j.plaphy.2011.06.008

5. Radchevsky P. P., Bessmertnaya M. V. Polythematic network electronic scientific Journal of the Kuban State Agrarian University, 108:379-400 (2015).

6. M.M. Alsina., D.R. Smart., C. Stockert, F. De Herralde, C. Biel, R. Save, C. Negron, T. Bauerle, J. Exp. Bot., 62(1), 99-109 (2011) https://doi.org/10.1093/jxb/erq247

7. M. Wu, J. Wu, Y. Gan, Plant Growth Reg., 91, 169-174 (2020), https://doi.org/10.1007/s10725-020-00608-1

8. J. Wang, Y. Su, X. Kong, Z. Ding, X.S. Zhang, aBiotech, 1, 194-204 (2020) https://doi.org/10.1007/s42994-020-00020-3

9. X. Sun, F. Chen, L. Yuan, G. Mi, Planta, 251, 84 (2020) https://doi.org/10.1007/s00425-020-03376-4

10. G. Jang, S. Lee, S. H. Chang, J.K. Kim, Y.D. Choi, Plant Biotech. Rep., 12, 265-271 (2018) https://doi.org/10.1007/s11816-018-0491-X

11. K.Danova, V. Motyka, M. Todorova, S. Krumova, P. Dovrev, T. Andreeva, T. Oreshkova, S. Tanieva, L. Evstatieva, J Plant Growth Regul., 37, 403-418 (2018) https://doi.org/10.1007/s00344-017-9738-y

12. D.F. Rovere, L. Fattorini, S. D'Angeli, G. Falasca, M. Altamura, Annals of Bot., 112(7), 1395-1407 (2013) https://doi.org/10.1093/aob/mct215

13. R. Ursache, Y. Helariutta, K. Nieminen, Phys. Plant. 147(1), 36-45 (2013) https://doi.org/10.1111/j.1399-3054.2012.01627.x

14. V.G. Ambrosini, J.J. Comin, D.J. Rosa, D.G. Simão., G. Brunetto, Plant Phys. Bioch. 96, 270-280 (2015) https://doi.org/ 10.1016/j.plaphy.2015.08.012

15. A.A. Ermakov, V.V. Chernova, A.V. Doroshkov, S.S. Sangaev, N.A. Omelyanchuk, A.V. Kochetov, V.V. Mironova, J. Stress Phys. Biochem., 8(3), 22 (2012) http://www.jspb.ru/issues/2012/N3/JSPB 20123 S22.pdf 